\title{
"Comparison of the digital economy development parameters in the EU countries in the context of bridging the digital divide"
}

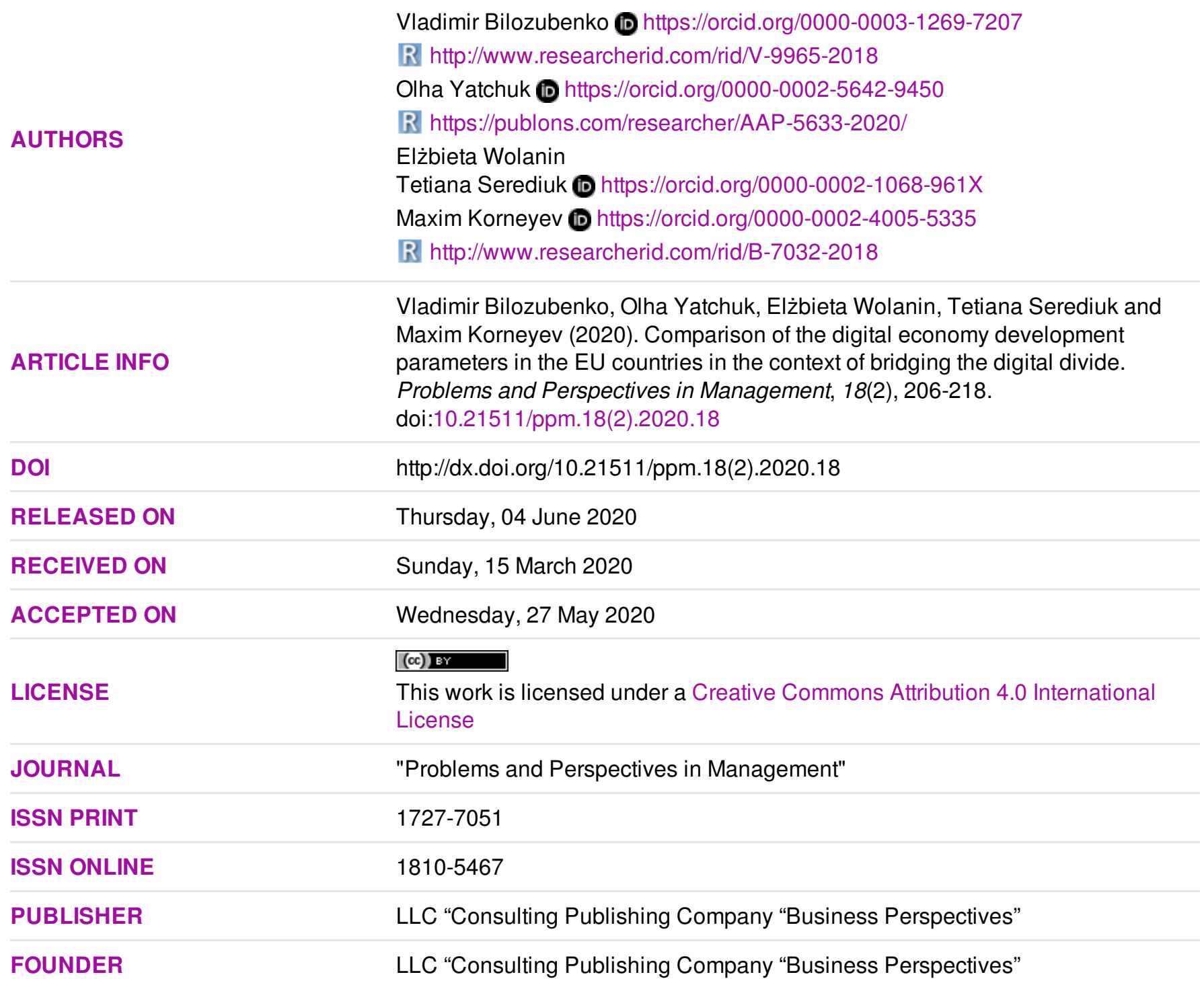

NUMBER OF REFERENCES

42
NUMBER OF FIGURES

0

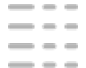

NUMBER OF TABLES

3

(C) The author(s) 2022. This publication is an open access article. 


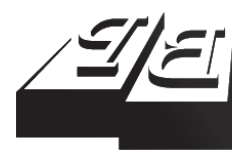

\section{BUSINESS PERSPECTIVES}

LLC "CPC "Business Perspectives" Hryhorii Skovoroda lane, 10, Sumy, 40022, Ukraine www.businessperspectives.org
Received on: $15^{\text {th }}$ of March, 2020 Accepted on: 27th of May, 2020 Published on: $4^{\text {th }}$ of June, 2020

(๑) Vladimir Bilozubenko, Olha Yatchuk, Elżbieta Wolanin, Tetiana Serediuk, Maxim Korneyev, 2020

Vladimir Bilozubenko, Doctor of Economic Science, Associate Professor, Head of the Department of International Economic Relations, Regional Studies and Tourism, University of Customs and Finance, Ukraine.

Olha Yatchuk, Ph.D. in Social Communications, Associate Professor of the Department of Psychology and Journalism, University of Customs and Finance, Ukraine.

Elżbieta Wolanin, Master, Department of Quantitative Methods, Faculty of Management, Rzeszow University of Technology, Poland.

Tetiana Serediuk, Master, Group Head of Marketing at Noosphere, United States of America.

Maxim Korneyev, Doctor of Economic Science, Professor, Professor of the Department of International Economic Relations, Regional Studies and Tourism, University of Customs and Finance, Ukraine. (Corresponding author)

This is an Open Access article, distributed under the terms of the Creative Commons Attribution 4.0 International license, which permits unrestricted re-use, distribution, and reproduction in any medium, provided the original work is properly cited.

Conflict of interest statement Author(s) reported no conflict of interest
Vladimir Bilozubenko (Ukraine), Olha Yatchuk (Ukraine), Elżbieta Wolanin (Poland) Tetiana Serediuk (United States of America), Maxim Korneyev (Ukraine)

\section{COMPARISON OF THE DIGITAL ECONOMY DEVELOPMENT PARAMETERS IN THE EU COUNTRIES IN THE CONTEXT OF BRIDGING THE DIGITAL DIVIDE}

\begin{abstract}
The widespread use of information and communication technologies and subsequent transformations have led to the formation of a digital economy (DE). The European Union, as an international organization, has become the subject of building such an economy, striving to bring member countries closer in the field of digitalization.

The aim of this paper is to compare the DE development parameters of the EU countries based on cluster analysis and determine the most significant of them to solve the problems of bridging the digital divide between countries. For clustering, a feature $\mathrm{DE}$ vector of 20 indicators was created and the k-means algorithm and the Euclidean distance metric were used. For classification, the decision tree method was applied.

Three clusters of EU countries were identified by the level of DE development (leaders, followers and outsiders), which allowed assessing their positions relative to each other. Key parameters that determine countries' positions in the general rating are identified. A parameter chart is generated to control the establishment of $\mathrm{DE}$ in the EU countries, which, in addition to key parameters, includes maximum, minimum and harmonic mean values of these parameters by cluster. This characterizes the landscape of DE development in the EU countries, assesses the digital divide and is the basis for decisionmaking in the area of bridging this divide.
\end{abstract}

\section{Keywords}

digital economy, digital divide, clustering, key parameters, parameter chart, governance

\section{JEL Classification $\quad \mathrm{C} 38, \mathrm{O} 11, \mathrm{O} 57$}

\section{INTRODUCTION}

In the modern economy, information and communication technologies (ICT) have an important structural and organizational value, making a significant contribution to economic growth and social progress. Over the past two decades, the Internet has developed rapidly, and various processes in the field of economic exchange, management and information have been transferred to this network. New generations of ICTs are becoming the basis for the Fourth Industrial Revolution, which is associated with robotics, the use of additive technologies, artificial intelligence, and the development of the Internet of things. Relevant digital transformations affect many sectors of the economy and create the infrastructure for trade, education, medicine, government and other services. As a result, digital economy (DE) is being shaped, followed by a new quality of relations, organization, management, new points and growth drivers. It is commonly agreed that the formation of $\mathrm{DE}$ is the cornerstone for overcoming the existing recession and moving on to the next long economic cycle. In terms of the scope of changes, DE can be safely attributed to the global 
megatrend of socio-economic development, which creates new benchmarks and priorities for countries, forming an appropriate agenda for the transition to this type of economic system.

The formation of $\mathrm{DE}$ has become an important strategic management task for countries adhering to global paths. One of the baselines of this is a comparison of the level of DE development in different countries, which reflects their position relative to each other both as a whole and specifically. This is necessary to overcome the unevenness of digital transformations, that is, the digital divide that arises between countries, given the complex nature of DE. It is critical to solve the scientific and practical problem of comparing DE development parameters in countries in order to improve positions in relevant international ratings to attract resources, create competitive advantages or evaluate the digitalization effectiveness, including in terms of monitoring the effectiveness of government control.

International organizations, in particular integration ones, which bring together large groups of countries, adhere to global trends and have become new actors in the development of DE. A vivid example of this is the European Union (EU), which pursues a focused policy in the field of building a digital economy and society, creates a single digital market, and strongly supports digital transformations in member countries. For the EU, it is important not only to ensure that member countries adhere to a single strategic course, but also to achieve common progress and convergence in the field of digitalization. In addition to global aspects, this includes bridging the digital divide between countries, which requires special approaches to assessing and setting benchmarks.

To solve the problem of comparing DE parameters (indicators) in the EU countries, it is proposed to use cluster analysis, which divides the countries, according to the development level of DE, into the following groups (clusters) - leaders, followers and outsiders. Classification of the obtained clusters will separate the parameters that most determine their classification, and they can be considered priority for increasing in order to bridge the digital divide. This analytical approach, along with the existing ones (mainly ratings for the EU, primarily The Digital Economy and Society Index of the European Union, DESI), will be useful in formulating appropriate policies at the level of member states and the EU as a whole, as well as various analytical studies.

\section{LITERATURE REVIEW}

In recent decades, attention to the role and importance of ICT in the economy has been steadily growing. As a result of the information revolution, a new era has arisen, an era of informatization, which has created new development horizons for all countries (Nasko, 2004). The main attention began to be paid primarily to increasing productivity through the use of ICTs, maximizing their impact on economic growth and finding ways to develop information infrastructure (Biagi, 2013). ICTs have gradually become one of the main factors of socio-economic progress, causing structural, institutional and organizational changes and acting as a prerequisite for the development of human potential (Njoh, 2018). The positive impact of ICTs was used purposefully, which led to their widespread use in the economy and, thus, the formation of its new structure and transition from industrial to digital economy (Zhu, 2019). The scale of the corresponding changes observed in more difficult years made it possible to consider a new trend - the Fourth Industrial Revolution (Industry 4.0), which is based on digital transformations of the social production system (Pereira \& Romero, 2017). Both developed and developing countries seek to switch to DE, gaining momentum to modernize the economic system and extracting additional opportunities for intensification (Amuso, Poletti, \& Montibello, 2019). The growing volumes of investment in the formation of $\mathrm{DE}$, the scale of the transformations and the ambiguity of their consequences required strategic management.

The vectors of transformations that form $\mathrm{DE}$ are very diverse and include new models and formats of interaction based on ICT and the Internet. For example, digital platforms have become a 
new phenomenon; today they are one of the key components of global economic exchange, creating new market mechanisms (Richardson, 2020). The next element was information sharing systems, which created a new method of transactions, wide opportunities for exchange and cooperation (Sutherland \& Jarrahi, 2018). A cyclical economy is highlighted as a new organizational model related to DE, the formation of which also involves the use of ICTs (Bressanelli, Adrodegari, Perona, \& Saccani, 2018). Informatization allows creating new business models necessary for the functioning of a cyclical economy, providing advantages in the context of new requirements (Pagoropoulos, Pigosso, \& McAloone, 2017). Economy digitalization has embraced the entrepreneurial sector, changing its traditional forms, and has led to a new type of business - digital entrepreneurship (Nwaiwu, 2018). This has also opened up new areas and opportunities for innovation (Nambisan, Wright, \& Feldman, 2019). The proliferation of new ICTs and related (digital) innovations has become an urgent issue for all countries (Park, 2017).

Although ICTs are developing rapidly, their distribution is uneven (Doong \& Ho, 2012). Both developed and developing countries create their own strategies to build DE (Larson, 2017; Etoundi, Mani Onana, Olle Olle, \& Ayissi Eteme, 2016; Abuladze \& Gigauri, 2017; Berdykulova, Sailov, Kaliazhdarova, \& Berdykulov, 2014). In the global and regional landscape, the progress of individual countries can be evaluated relative to other states (Myovella, Karacuka, \& Haucap, 2019). ICT development, leaders and core capabilities are naturally concentrated in developed countries. However, lagging countries also have to step up and improve their national digital policies (Foster \& Azmeh, 2019). For these countries, the assessment of DE development parameters is especially relevant, including in comparison with developed countries. This is important for bridging the global economic disparities caused by technological gaps, including digital.

The concept of the digital divide was originally proposed at the turn of the 20th and 21st centuries to describe the inequality between people who have access to the Internet and those who do not. Over time, the reading of the digital divide has become more diverse, wider, covering not on- ly access issues, but also the use of ICTs, the construction of the necessary infrastructure, which, in turn, characterizes the level of $\mathrm{DE}$ development. The digital divide began to be considered globally, covering primarily developed and developing countries, as well as various regions of the world (Antonelli, 2003; Chen \& Wellman, 2004). It is also advisable to consider it on the scale of individual regions of the world, first of all, within the framework of regional integration organizations, where there are institutional foundations and the economic need for technological convergence and the corresponding management needs for comparing DE parameters by country. Assessing the digital divide based on comparative analysis allows you not only to establish differences, but also to evaluate the priority areas for $\mathrm{DE}$ development, achieving a more rational use of resources.

It is important for countries to make digitalization a benefit and give impetus to socio-economic progress. This has created a new management area and required additional functions of the state (Hanna, 2018; Rumana \& Richard, 2018). The digital world needed special strategies for the sustainable development of DE that could be implemented by states and international organizations (Linkov, Trump, Poinsatte-Jones, \& Florin, 2018). To ensure the transition to DE, long-term planning is increasingly being used, which necessarily includes an assessment of DE development (Sturgeon, 2019). In addition to procedures, the management of $\mathrm{DE}$ development itself requires appropriate monitoring methods, methods for assessing dynamics, approaches to substantiating indicative or target factors, measuring effects, etc. Nationally, this is primarily a change in the level of $\mathrm{DE}$ development, which can be carried out through a comparative analysis (Moroz, 2017). Comprehensive international indices and ratings are widely used in this area, reflecting the levels of $\mathrm{DE}$ development in general and by component in particular (Pratipatti \& Gomaa, 2019). However, rated products do not always give a complete picture and it is advisable to supplement them.

A comparative analysis in assessing the level of $\mathrm{DE}$ development at the regional level is of particular importance, since it allows distinguishing differences within the region, which is relevant for European countries (Balcerzak \& Pietrzak 
Bernard, 2017). In the EU, which unites many countries, it is advisable to assess the digital divide based on a multilevel approach, in particular, considering the differences between the new and old member countries (Szeles, 2018). The digital divide between countries can also be assessed at the individual level, covering the use of ICT by the population and business (Chipeva, Cruz-Jesus, Oliveira, \& Irani, 2018), as well as at the household level (Lucendo-Monedero, Ruiz-Rodríguez, \& González-Relaño, 2019), which is necessary for understanding the sources, landscape and magnitude of differences.

Approaches to measuring $\mathrm{DE}$ are becoming more diverse and improved. However, objective difficulties remain in assessing this phenomenon, especially given the multidimensionality and rapid development of digitalization. This is also due to objective problems of using traditional economic indicators for DE, including GDP statistics, difficulties in understanding the values of digital goods and services, etc. (Brynjolfsson \& Collis, 2019). Special studies propose analytical frameworks (Ahmad \& Ribarsky, 2018) and statistical methods (Bukht \& Heeks, 2018) for measuring $\mathrm{DE}$. The same problem exists at the industry level (Borouji Hojeghan \& Nazari Esfangareh, 2018). DE measurements are quite extensive due to the multidimensional nature and the diverse impact of ICT on the economy. Fields of measurement include the rate at which countries or industries switch to DE, structural changes and economic impacts, evaluation of benefits received, etc. Leading international organizations are paying more attention to DE measurements. G20, OECD, UNCTAD, International Monetary Fund, World Economic Forum, and International Telecommunication Union carry out special monitoring, which is the basis for developing international initiatives and recommendations for countries.

Transition to DE is also a priority issue for the European Union. This is defined as a strategic benchmark for the socio-economic progress of Europe, which is reinforced by a focused supranational policy to stimulate digital transformations. The EU makes efforts to boost DE of its member countries, especially those lagging behind. Assessing the DE progress of countries includes not only individual profiles, but also is largely based on a comparative analysis.
The evaluation of DE parameters and its consequences in the $\mathrm{EU}$ is considered in a wide context, especially in terms of the development of the European Digital Single Market, ensuring sustainable growth, improving wealth, developing human capital, stimulating innovation, and transforming the state. The experience of the $\mathrm{EU}$ and individual countries is of great interest both regionally and globally (Milošević, Dobrota, \& Barjaktarovic Rakocevic, 2018; Veld, 2019; Gruber, Hätönen, \& Koutroumpis, 2014; Gruber, 2019). The EU has created a statistical monitoring system for DE estimates for member countries and other states that are global leaders, major players or neighbors. The EU has developed its own Digital Economy and Society Index (DESI) to measure digital performance and changes based on country comparisons. However, the rating leads to the omission of certain analytical capabilities that will be shown in this paper.

A brief review allows one to talk about the growing attention to DE, which has formed a separate research area, covering all levels of economic systems, and the consequences of the emergence of this new type of economy. However, the problem of measuring DE, which includes many aspects and tasks, is solved fragmentarily.

A modern dynamic and open economy requires more sophisticated measurement approaches. Rated products that spread quickly showed objective utility, and in many areas have become a major monitoring tool, including DE (for example, DESI). The ratings presented today, simple and complex, transparent and opaque, are evaluated differently in terms of practice. However, despite skepticism (such as Goodhart's law), the need for ratings has made rating comparisons an integral part of scientific and analytical research. Meanwhile, rated products do not exclude the use of other comparative analysis approaches, and often even push them to development, including in the field of comparisons.

Considering the problem of measuring DC, one can distinguish the following unresolved parts: 1) lack of agreed methodologies or a single holistic approach to assessing the development level of $\mathrm{DE}$ of countries; 2) restricted application of a comparative analysis while exploring parameters of the 
formation and development of DE in countries; 3 ) incomplete explanation and quantification of the digital divide between countries, as well as its various manifestations; 4) lack of a holistic methodology for positioning countries according to their level of DE development. Traditional statistical methods and index approaches as a whole are not questioned, but they can be significantly supplemented by Data Mining methods - clustering and classification, which will significantly strengthen analytical capabilities.

\section{AIMS}

The purpose of this paper is to compare DE development parameters in the EU countries based on clusterization, highlighting the clusters of leaders, followers and outsiders, and to determine, based on the classification analysis, parameters that are most significant in separating the clusters and are priority for bridging the digital divide.

\section{METHODS}

It should be borne in mind that the objectization, capabilities and tools of assessment (measurement) largely determine the ability to effectively manage. It is supposed to analyze not so much the objects themselves as a set of special parameters reflecting their properties, in a certain proportion. That's what accounts for the informational approach to cognition, according to which the most important regularities determining the development of objects and presented by empirical data are identified and analyzed. Correlation, comparison, analysis and synthesis of regularities create the basis for the information approach.

There are natural difficulties in measuring DE, especially at the global and international and regional levels, where there is an extensive range of diverse objects. When it comes to countries, then the level of DE development is often advisable to evaluate relative to other countries, which is more specific and informative. This is especially true for the EU, whose member countries are closely connected institutionally within a single supranational organization, economic policy and international projects, which requires special attention to assessing the digital divide. $\mathrm{DE}$ development in a particular country is understood as the level of access and use of ICTs in different areas, which is expressed by the corresponding empirical data.

Evaluating DE development parameters for the EU countries involves the search for regularities (a certain structure) in the available data, based on the possible object similarity. If the set of objects can be objectively divided into clusters, then differences between these groups can be distinguished, which will allow determining the parameters that are most significant for their separation. This is achieved through a combination of clustering and classification, which are the main tasks of Data Mining and allow using hidden methods to search for hidden patterns in large data sets.

Clustering and classification can be attributed to the general scientific methods of cognition, reflecting ideas about the variety of objects (objects of nature or social phenomena), their similarities, differences and relationships. Thus, these methods allow one to show the correlation of parts (EU countries) with each other and with the whole (average EU level). Clustering and classification form the basic level of the methodology of science, making it possible to find underlying patterns, determine causality, establish new cause-effect relationships, objects' properties, as well as predict. The applicability of clustering and classification is based on hypotheses that are common to different subject areas. First of all, this is the compactness hypothesis, namely the assumption that similar objects more often lie in one cluster (class) than in different ones; therefore, compactly localized subsets arise in the space of objects. The compactness hypothesis as applied to the task and the subject area gives rise to working hypotheses about the positive relationship of the selected indicators, their contribution to DE development and the possible significant similarities between countries.

Let us proceed to some methodological issues of the proposed approach.

Clustering of EU countries by DE development parameters. Clustering is the primary goal of Data Mining and relates to learning without a teacher, or unsupervised learning. The purpose is to see the objective structure without the initial 
division of objects into classes (automatic classification). Clustering is intended to divide a set of objects into objectively existing homogeneous groups, clusters, by the similarity of their parameters. To assess the level of DE development by country, clustering supplements the existing index approaches, reflecting the positioning of countries relative to each other. The level of DE development of each EU country will be assessed based on its attribution to a specific cluster (leaders, followers and outsiders).

Given the complex nature of the country's DE, a large set of parameters (attributes) is used to describe it. The attribute $x$ means a discrete description of a certain feature of the studied object $X$ (DE of a country), which allows structuring many objects (countries). Thus, the basis for clustering is a feature description of objects. It is assumed that each object $X$ is described using a set of characteristic values $x_{1}, \ldots, x_{n}$, that is, it is a vector and is represented by dimension $n$, on the axes of which the values of these signs are located. Object $X$ means a set $\mathrm{X}=\left(\mathrm{x}_{1}, x_{2}, \ldots, \mathrm{x}_{n}\right)$ of discrete values of attributes (a discrete set of $X$ ). A feature description is an object-property table (OPT), that is, a table whose rows are objects and columns are properties of these objects. OPT is developed based on synthesizing official statistics that characterize the country's DE. A structured set of features available for evaluation carries a greater amount of information than each of them individually. This allows one to search for regularities. The informational nature of the feature description allows representing OPT as a training sample of valid data for clustering. Following the empirical principle, the feature description satisfies three conditions: consistency, completeness (in describing all aspects of an object), simplicity (the number of initial elements should be minimal) and sufficiency in describing an object. When compiling a feature description, the mutual influence of features was not considered, but horizontal equality and the equal significance of all parameters were taken into account. To supplement rating approaches, only basic indicators of official statistics were included in the sample. The list of indicators to describe DE of the EU countries (without the United Kingdom) summarizes the data of Eurostat, World Bank and UNCTADstat (see Table 1).

\section{Table 1. EU DE feature description}

\section{Internet connection and computer use (Eurostat)}

1. Households - level of Internet access, \%.

2. Households - type of Internet connection (broadband), $\%$.

3. Individuals - mobile Internet access (individuals using a laptop, notebook, netbook or tablet computer to access the Internet away from their home or work), \%.

\section{ICT usage by households and individuals (Eurostat)}

4. Individuals - Internet use (last Internet use: in the last 12 months), \%.

5. Individuals - frequency of Internet use (frequency of internet access: daily), \%.

6. Individuals - use of cloud services (used Internet storage space to save documents, pictures, video or other files), \%.

7. Individuals - collaborative economy (an individual who used any website or app to arrange an accommodation from another individual), \%.

8. Internet purchases by individuals (last online purchase: in the last three months), \%.

9. E-government activities of individuals via websites (Internet use: Internet with public authorities (last 12 months)), \%.

\section{Digital skills (Eurostat)}

10. Individual level of digital skills (individuals who have basic or above basic digital skills), \%

11. Enterprises that employ ICT specialists (all enterprises, without financial sector (10 persons employed or more)), $\%$.

12. Employed ICT specialists - total, \% of total employment.

13. Enterprises that provided training to develop/upgrade ICT skills of their personnel (all enterprises, without financial sector (10 persons employed or more)), \%.

14. Employed persons with ICT education, \%.

Digital single market - promoting e-commerce for individuals (Eurostat)

15. Broadband and connectivity - persons employed (al enterprises, without financial sector (10 persons employed or more)), \% of total employment.

16. E-commerce, customer relation management (CRM) and secure transactions (all enterprises, without financial sector (10 persons employed or more)), \% of enterprises.

Participation in international trade in the field of ICT (World Bank and UNCTADstat)

17. Imports of ICT goods (\% total imports of goods).

18. Exports of ICT goods (\% of total exports of goods).

19. Export in ICT services, \% of total export in services.

20. Import in ICT services, \% of total import in services.

Note: Indicators 1 to $11,13,15,16$ - the year 2019; indicators $12,14,19,20$ - the year 2018; indicators 17, 18 - the year 2017. Finland - indicator 3 , Slovakia -10, Netherlands -13 the year 2018. Malta - 17 and 18 - the year 2016. Lithuania, Luxembourg and Malta - indicator 19 - the year 2017. Belgium, Spain, Lithuania, Luxembourg, Malta, Austria, and Sweden - indicator for 2017.

In the feature description, the indicators are heterogeneous and specific, reflect essential characteristics, explain various components, aspects and processes of $\mathrm{DE}$. The indicators are interconnected by one subject area, however, the nature of the relationship (dependence) between them cannot be assumed. There are no conflicting indicators and indicators at which saturation or minimal demand is possible. All indicators are subject to 
the maximization imperative, taking into account performance criteria. Meanwhile, indicators have lower and upper empirical limits across the entire population of countries and will have the same limits for clusters. Given the high quality of available official statistics (Eurostat, World Bank and UNCTAD), the prepared data sample is relevant for macroeconomic analysis. Statistics are prepared systematically, so the methodology can be applied to other periods.

Given the specifics of the data set, for the country clusterization, a $k$-means algorithm was chosen that is effective when the data form compact aggregations and are very different from each other (Everitt, Landau, Leese, \& Stahl, 2011). The data were normalized. The criterion for the object similarity is the distance between them. Euclidean distance is chosen as a metric. To get correct results, one needs to check the data quality and determine the optimal number of clusters. The clusters that will be found will be classes, and an OPT, due to such structuring, will be converted into a training sample (TS), which will be the basis for classification.

Determining parameters that distinguish clusters of EU countries in terms of DE development, based on classification analysis. Classification is generally understood as a reasonable distribution of the studied objects by type based on any essential attributes that describe their features (creating descriptions). The classification should be subject to specific research and/or managerial goals, which determines the basis for the selection of characteristics and distribution. As a result of the classification, a regularity or rule (several regularities or rules) is revealed that allows one to conclude on determining the characteristics of a particular group of objects and the causal dependence of one group on another group. Classification is closely related to clustering, as it involves the arrangement of objects in a certain order, reflecting their similarity degree. This allows attributing an object, which is new to this population, to a specific class (a recognition procedure). The mathematical and classification treatment of data is the basis for the division. The significance and role of individual parameters are not considered. Classification can be set initially (learning with a teacher) or carried out using clustering. Clustering is necessary for dividing objects into clusters (classes), and classification is for finding differences between clusters and, accordingly, between objects included in them.

In this paper, classification is aimed at searching for parameters that distinguish all clusters of a given set of objects and, thus, determining the position of each country in the general rating, which allows us to understand the leadership architecture (that is, they determine the level of DE development to a greater extent) and the reason for the digital divide. It is proposed to use this aspect of classification in management, since classification processing makes it possible to choose from a sufficiently large set of indicators those that are priority for increasing. Some countries can use this in their management to increase the level of DE development and improve their position in the overall ranking (moving to a cluster of more successful countries) as quickly and efficiently as possible, because from the whole set they get a relatively small set of parameters that should be increased in the first instance. This allows them to focus efforts and resources on priority indicators. In general, this also solves EU-level governance problems, creating a supranational DE development policy and more effectively striving to bridge the digital divide. This serves as a reliable basis for governance, which is improved due to the accuracy and understanding of the feasibility of increasing the priority group indicators, taking into account their significance.

For classification, a logical combinatorial method (decision trees) was used, which was theoretically justified and practically confirmed its effectiveness (Vasilenko \& Shevchenko, 1979). The data source will be a TS (an empirical data table consisting of many discrete sets of $X$, for each of which belonging to a particular class is known), resulting from the clustering based on feature description (see Table 1). The proposed approach allows evaluating the information content of both individual parameters and their random groups, and identifying those that indicate significant differences between the found classes (clusters). The contribution of individual parameters is estimated by the following formula, which is a criterion for choosing parameters with the highest discriminatory significance: 


$$
V\left(x_{i 1}, \ldots, x_{i j}\right)=\frac{1}{k} \sum_{\Delta \in \Gamma} \max _{Y}\left(\frac{m_{\Delta Y}}{m_{Y}}\right),
$$

where $k$ is the number of classes (clusters), $m_{Y}$ is the number of objects belonging to a class (cluster) $Y \quad \Delta=t_{i 1}, t_{i 2}, \ldots, t_{i j}\left(0 \leq t_{i j} \leq k_{i j}-1\right)$, $j=1, \ldots, \Gamma$ means the arbitrary set of parameter values $x_{i 1}, \ldots, x_{i j}(1 \leq \Gamma \leq n), m_{\Delta Y}$ denotes the number of sampling sets of the $m$ class, for which the relation $x_{i j}=t_{i j}(j=1, \ldots, \Gamma)$ is performed, $t_{i j}$ are the values of parameters $x_{i j}$ in the set of $\Delta, \Gamma$ means variety of all sets of parameter value $x_{i 1}, \ldots, x_{i j}$.

Formula (1) allows one to calculate the distinguishing ability of the entire training sample and highlight the informative characteristic groups (ICG), which have the maximum distinguishing ability. In fact, ICGs are the main indicators that determine the positioning of countries in a general rating and are priority for increasing to bridge the digital divide. With complete class distinguishability, this estimate takes on the value of 1 . In the presented data set, 20 parameters characterizing DE are used. Therefore, in the extreme case, even when using only binary data encoding, which is necessary to simplify the classification processing of TS, a comprehensive search for groups of key parameters will require verification of 20 different parameter combinations. Finding an ICG solves the problem of identifying key features and allows reducing the exhaustive search of parameters. Based on the presented mathematical approach, the resulting clusters of the EU countries will be classified in accordance with $\mathrm{DE}$ development parameters. The procedure for searching for ICG and assessing their significance is implemented as a service on the ScienceHunter portal (URL: http://sciencehunter.net).

Developing a parameter chart to govern the establishment of DE for EU countries. Clustering will result in objectively distinguished clusters, and classification will result in a subgroup of key parameters that separate classes (clusters) and an assessment of the significance of each of the ICGs. Based on this, a parameter chart to control the DE establishment will be compiled: for each cluster, the maximum, minimum and harmonic means for the EU will be determined, which will allow for more detailed identification of the countries' positions within the clusters and show the lag (digital divide) from the leaders of this group and a cluster of more successful countries, which will highlight the corridors for the necessary increase in parameters. A parameter chart can become an additional decision-making tool as part of macroeconomic governance in the context of individual countries and the EU as a whole. Such a chart can be supplemented by well-known international indices reflecting DE development in the EU countries. All these steps can be directly moved to the practical field as a method that facilitates the adoption of various decisions: setting goals, defining targets, planning, monitoring, and regulation.

\section{RESULTS}

Based on the proposed feature description (see Table 1) and collected empirical data, OPT is obtained and clustering is carried out ( $k$-means is a method, Euclidean distance is a metric). Previously, using three-dimensional visualization based on the main component method, multidimensional scaling, and as a set of design criteria, the optimal number of clusters - three - is determined. To do this, data mining tools on the ScienceHunter portal (URL: http://sciencehunter.net) are used. Clustering confirmed the objectivity of dividing countries into groups (clusters), which made it possible to pose the problem of finding differences between them. The three clusters obtained, depending on the value of $\mathrm{DE}$ parameters, are defined as leaders, followers and outsiders.

As a result of the classification processing based on ScienceHunter tools (the quality of the training sample is $100 \%$; the share of the examining sample is $10 \%$ ), five parameters were selected that gave $100 \%$ cluster division in total: 1 ) households - the level of internet access, \% $\left(x_{1}\right)$; 2) individuals - mobile internet access, $\%\left(x_{3}\right)$; $3)$ individuals - internet use, $\%\left(x_{4}\right)$; 4) enterprises that employ ICT specialists, $\%\left(x_{11}\right)$; and 5 ) enterprises that provide training to develop/ upgrade ICT skills of their personnel, \% $\left(x_{13}\right)$. All of them are key parameters of the digital di- 
Table 2. Parameter chart to manage DE development in EU countries

\begin{tabular}{|c|c|c|c|c|c|}
\hline $\begin{array}{c}\text { EU member } \\
\text { states }\end{array}$ & $\begin{array}{l}\text { Households - } \\
\text { level of Internet } \\
\text { access, } \%\end{array}$ & $\begin{array}{c}\text { Individuals - } \\
\text { mobile Internet } \\
\text { access }\end{array}$ & $\begin{array}{l}\text { Individuals } \\
\text { - Internet } \\
\text { use }\end{array}$ & $\begin{array}{l}\text { Enterprises } \\
\text { that employ } \\
\text { ICT specialists }\end{array}$ & $\begin{array}{l}\text { Enterprises that provided } \\
\text { training to develop/upgrade } \\
\text { ICT skills of their personnel }\end{array}$ \\
\hline \multicolumn{6}{|c|}{ Cluster I (leaders) } \\
\hline Belgium & 90.00 & 57.00 & 91.00 & 28.00 & 36.00 \\
\hline Denmark & 95.00 & 58.00 & 97.00 & 30.00 & 31.00 \\
\hline Germany & 95.00 & 52.00 & 94.00 & 19.00 & 32.00 \\
\hline Ireland & 91.00 & 44.00 & 91.00 & 32.00 & 31.00 \\
\hline Luxembourg & 95.00 & 42.00 & 97.00 & 25.00 & 27.00 \\
\hline Netherlands & 98.00 & 49.00 & 96.00 & 26.00 & 26.00 \\
\hline Finland & 94.00 & 39.00 & 95.00 & 26.00 & 37.00 \\
\hline Sweden & 96.00 & 49.00 & 98.00 & 18.00 & 32.00 \\
\hline $\max$ & 98.00 & 58.00 & 98.00 & 32.00 & 37.00 \\
\hline $\mathrm{hm}$ & 94.19 & 47.90 & 94.81 & 24.58 & 31.09 \\
\hline $\min$ & 90.00 & 39.00 & 91.00 & 18.00 & 26.00 \\
\hline \multicolumn{6}{|c|}{ Cluster II (followers) } \\
\hline Czech Republic & 87.00 & 31.00 & 88.00 & 20.00 & 25.00 \\
\hline Estonia & 90.00 & 33.00 & 91.00 & 15.00 & 17.00 \\
\hline Spain & 91.00 & 37.00 & 91.00 & 17.00 & 22.00 \\
\hline France & 90.00 & 48.00 & 91.00 & 17.00 & 21.00 \\
\hline Cyprus & 90.00 & 29.00 & 86.00 & 23.00 & 31.00 \\
\hline Latvia & 85.00 & 16.00 & 87.00 & 20.00 & 18.00 \\
\hline Lithuania & 82.00 & 28.00 & 82.00 & 15.00 & 11.00 \\
\hline Hungary & 86.00 & 47.00 & 83.00 & 26.00 & 16.00 \\
\hline Malta & 86.00 & 48.00 & 86.00 & 27.00 & 26.00 \\
\hline Austria & 90.00 & 47.00 & 88.00 & 20.00 & 18.00 \\
\hline Poland & 87.00 & 34.00 & 82.00 & 23.00 & 13.00 \\
\hline Slovenia & 89.00 & 22.00 & 84.00 & 18.00 & 28.00 \\
\hline Slovakia & 82.00 & 40.00 & 85.00 & 18.00 & 18.00 \\
\hline $\max$ & 91.00 & 48.00 & 91.00 & 27.00 & 31.00 \\
\hline $\mathrm{hm}$ & 87.21 & 31.99 & 86.35 & 19.27 & 18.70 \\
\hline $\min$ & 82.00 & 16.00 & 82.00 & 15.00 & 11.00 \\
\hline \multicolumn{6}{|c|}{ Cluster III (outsiders) } \\
\hline Bulgaria & 75.00 & 25.00 & 71.00 & 20.00 & 10.00 \\
\hline Greece & 79.00 & 25.00 & 76.00 & 22.00 & 15.00 \\
\hline Croatia & 81.00 & 22.00 & 80.00 & 19.00 & 23.00 \\
\hline Italy & 85.00 & 14.00 & 78.00 & 16.00 & 19.00 \\
\hline Portugal & 81.00 & 34.00 & 76.00 & 21.00 & 28.00 \\
\hline Romania & 84.00 & 32.00 & 80.00 & 10.00 & 6.00 \\
\hline $\max$ & 85.00 & 34.00 & 80.00 & 22.00 & 28.00 \\
\hline $\mathrm{hm}$ & 80.70 & 23.30 & 76.71 & 16.75 & 12.90 \\
\hline $\min$ & 75.00 & 14.00 & 71.00 & 10.00 & 6.00 \\
\hline
\end{tabular}

vide between EU countries. Therefore, based on these parameters, a parameter chart to manage $\mathrm{DE}$ development is created, which includes the data of each country, as well as the maximum $(\max )$, minimum (min) and harmonic mean $(\mathrm{hm})$ values for the clusters (see Table 2). This shows the DE development and digital divide landscape. 


\section{DISCUSSION}

The results of the study show which parameters were key for DE development in the EU countries, ensured the distribution of countries by level, identified the similarity of individual clusters and, therefore, are priority for increase to bridge the digital divide. The parameter chart allows each country to understand what parameters and to what extent it needs to increase in order to move to a cluster with more successful states (and when it comes to leaders, how they can maintain their positions). In general, it allows: 1) improving control effectiveness by focusing efforts and resources on priority parameters; 2) identifying targets for strategic management; 3) evaluating the digital divide patterns, the prerequisites for changing countries' positions and the effectiveness of post factum management; 4) considering the pro- files of individual countries, determining their road map for developing DE and evaluating convergence problems at the EU level; 5) highlighting the points and drivers DE growth in the European economy; and 6) based on a set of key indicators, setting priority measures to develop DE. Similar calculations can be carried out on an annual basis to study changes in key indicators of DE development, be the basis for further theoretical research, since the key parameters obtained, linked into decision trees and reflecting cause-effect relationships, make it possible to develop and test new research hypotheses.

The resulting parameter chart complements rated products reflecting the level of DE development (see Table 3), by objectively dividing countries into leaders, followers and outsiders and understanding of the reasons for this.

Table 3. Values of existing ratings, which reflect DE, for EU countries with the distribution by clusters received

Source: The Digital Economy and Society Index, DESI https://ec.europa.eu/digital-single-market/en/desi. The Global Competitiveness Index 4.0, http://www3. weforum.org/docs/WEF_TheGlobalCompetitiveness Report2019.pdf. Global Innovation Index, https://www.globalinnovationindex.org/gii-2019-report

\begin{tabular}{|c|c|c|c|}
\hline $\begin{array}{l}\text { EU member } \\
\text { states }\end{array}$ & $\begin{array}{l}\text { Digital Economy and } \\
\text { Society Index, DESI }\end{array}$ & $\begin{array}{c}\text { ICT adoption (Global } \\
\text { Competitiveness Index 4.0) }\end{array}$ & $\begin{array}{c}\text { ICTs (Global } \\
\text { Innovation Index) }\end{array}$ \\
\hline \multicolumn{4}{|c|}{ Cluster I (leaders) } \\
\hline Belgium & 9 & 47 & 38 \\
\hline Denmark & 4 & 9 & 2 \\
\hline Germany & 12 & 36 & 15 \\
\hline Ireland & 7 & 49 & 23 \\
\hline Luxembourg & 6 & 20 & 5 \\
\hline Netherlands & 3 & 24 & 4 \\
\hline Finland & 1 & 13 & 16 \\
\hline Sweden & 2 & 4 & 12 \\
\hline \multicolumn{4}{|c|}{ Cluster II (followers) } \\
\hline Czech Republic & 18 & 42 & 64 \\
\hline Estonia & 8 & 16 & 20 \\
\hline Spain & 11 & 19 & 17 \\
\hline France & 15 & 28 & 10 \\
\hline Cyprus & 22 & 58 & 32 \\
\hline Latvia & 17 & 15 & 56 \\
\hline Lithuania & 14 & 12 & 43 \\
\hline Hungary & 23 & 54 & 54 \\
\hline Malta & 10 & 25 & 22 \\
\hline Austria & 13 & 50 & 26 \\
\hline Poland & 25 & 51 & 28 \\
\hline Slovenia & 16 & 40 & 39 \\
\hline Slovakia & 21 & 39 & 47 \\
\hline \multicolumn{4}{|c|}{ Cluster III (outsiders) } \\
\hline Bulgaria & 28 & 30 & 45 \\
\hline Greece & 26 & 52 & 35 \\
\hline Croatia & 20 & 60 & 57 \\
\hline Italy & 24 & 53 & 24 \\
\hline Portugal & 19 & 34 & 25 \\
\hline Romania & 27 & 32 & 63 \\
\hline
\end{tabular}




\section{CONCLUSION}

Based on the proposed feature description and clustering methods, the EU countries were divided into three clusters according to the level of DE development. As a result, leaders, followers and outsiders were identified reflecting the digital divide between them. Based on the classification analysis, key parameters are identified that are most significant in separating the clusters and thereby determine the position of countries in the general rating. These are indicators such as households - the level of internet access; individuals - mobile internet access; individuals - internet use; enterprises that employ ICT specialists; and enterprises that provide training to develop/upgrade ICT skills of their personnel. All these parameters are becoming a priority for countries that want to bridge the digital divide. This is important for management, since focusing on key parameters allows each country to effectively move into a cluster of more successful states, and at the EU level, it can effectively bridge the digital divide and achieve convergence. Based on the selected key parameters, a parameter chart is generated to manage DE establishment, which includes the data of each country, as well as the maximum, minimum and harmonic mean values for each cluster. The presented approach provides new opportunities in managing DE establishment, can be used as a methodology to analyze its development and the digital divide both in the EU countries and around the world, as well as to develop and evaluate the effectiveness of measures to ensure digital transformations. Further research is expected to improve the proposed parameter chart for controlling the establishment of DE based on cognitive modeling.

\section{AUTHOR CONTRIBUTIONS}

Conceptualization: Vladimir Bilozubenko, Maxim Korneyev.

Data curation: Olha Yatchuk, Elżbieta Wolanin, Tetiana Serediuk.

Formal analysis: Olha Yatchuk.

Investigation: Vladimir Bilozubenko, Tetiana Serediuk, Maxim Korneyev.

Methodology: Tetiana Serediuk.

Software: Olha Yatchuk.

Supervision: Vladimir Bilozubenko, Elżbieta Wolanin, Maxim Korneyev.

Visualization: Olha Yatchuk, Elżbieta Wolanin.

Writing - original draft: Elżbieta Wolanin, Tetiana Serediuk.

Writing - review \& editing: Vladimir Bilozubenko, Maxim Korneyev.

\section{REFERENCES}

1. Abuladze, R., \& Gigauri I. (2017). Ecosystem of Digital Economy in Georgia. SSRN Electronic Journal. http://dx.doi.org/10.2139/ ssrn. 2958038

2. Ahmad, N., \& Ribarsky, J. (2018) Towards a Framework for Measuring the Digital Economy. 16th Conference of the International Association of Official Statisticians (IAOS), (1-33). Paris: OECD Headquarters. Retrieved from http://www.oecd. org/iaos2018/programme/IAOSOECD2018_Ahmad-Ribarsky.pdf

3. Amuso, V., Poletti, G., \& Montibello, D. (2019). The Digital Economy: Opportunities and Challenges. Global Policy, 11(1), 124-127. https://doi.org/10.1111/17585899.12745

4. Antonelli, C. (2003). The digital divide: understanding the economics of new information and communication technology in the global economy. Information Economics and Policy, 15(2), 173-199. https://doi.org/10.1016/ S0167-6245(02)00093-8

5. Balcerzak, P. A., \& Michał, P. B. (2017). Digital Economy in Visegrad Countries. Multiple-criteria Decision Analysis at Regional Level in The Years 2012 and 2015. Journal of Competitiveness, 9(2), 5-18. https://doi.org/10.7441/ joc.2017.02.01
6. Berdykulova, G. M. K., Sailov, A. I. U., Kaliazhdarova, Sh. Y. K., \& Berdykulov, E. B. U. (2014). The Emerging Digital Economy: Case of Kazakhstan. Procedia - Social and Behavioral Sciences, 109, 1287 1291. https://doi.org/10.1016/j. sbspro.2013.12.626

7. Biagi, F. (2013). ICT and Productivity: A Review of the Literature. Luxembourg: Publications Office of the European Union.

8. Bressanelli, G., Adrodegari, F., Perona, M., \& Saccani, N. (2018). The role of digital technologies to overcome Circular Economy challenges in PSS Business Models: an 
exploratory case study. Procedia CIRP, 73, 216-221. https://doi. org/10.1016/j.procir.2018.03.322

9. Brynjolfsson, E., \& Collis, A. (2019). How Should We Measure the Digital Economy? Harvard Business Review. Retrieved from https://hbr.org/2019/11/howshould-we-measure-the-digitaleconomy

10. Bukht, R., \& Heeks, R. (2018). Defining, Conceptualising and Measuring the Digital Economy. International Organisations Research Journal, 13(2), 143-172. https://doi.org/10.17323/19967845-2018-02-07

11. Bukht, R., \& Heeks, R. (2018). Digital Economy Policy in Developing Countries. Paper No. 6. In Development Implications of Digital Economies. Centre for Development Informatics Global Development Institute, SEED. https://doi.org/10.13140/ RG.2.2.24272.15364

12. Chen, W., \& Wellman, B. (2004). The Global Digital Divide - Within and Between Countries. IT \& Society, 1(7), 39-45. Retrieved from http:// citeseerx.ist.psu.edu/viewdoc/ summary?doi=10.1.1.207.1713

13. Chipeva, P., Cruz-Jesus, F., Oliveira, T., \& Irani, Z. (2018). Digital divide at individual level: Evidence for Eastern and Western European countries. Government Information Quarterly, 35(3), 460-479. https://doi.org/10.1016/j. giq.2018.06.003

14. Doong, Sh. H., \& Ho, Sh.-Ch. (2012). The impact of ICT development on the global digital divide. Electronic Commerce Research and Applications, 11(5), 518-533. https://doi.org/10.1016/j. elerap.2012.02.002

15. Etoundi, R. A., Onana, F. S. M., Olle, G. D. O., \& Eteme, A. A. (2016). Development of the Digital Economy in Cameroon: Challenges and Perspectives. The Electronic Journal of Information Systems in Developing Countries, 76(1), 1-24. https://doi. org/10.1002/j.1681-4835.2016. tb00558.x
16. Everitt, B., Landau, S., Leese, M., \& Stahl, D. (2011). Cluster Analysis. Chichester, West Sussex: Wiley.

17. Foster, C., \& Azmeh, Sh. (2019). Latecomer Economies and National Digital Policy: An Industrial Policy Perspective. The Journal of Development Studies. https://doi.or g/10.1080/00220388.2019.1677886

18. Gruber, H. (2019). Proposals for a digital industrial policy for Europe. Telecommunications Policy, 43(2), 116-127. https://doi.org/10.1016/j. telpol.2018.06.003

19. Gruber, H., Hätönen, J., \& Koutroumpis, P. (2014). Broadband access in the EU: An assessment of future economic benefits. Telecommunications Policy, 38(11), 10461058. https://doi.org/10.1016/j. telpol.2014.06.007

20. Hanna, N. (2018). A role for the state in the digital age. Journal of Innovation and Entrepreneurship, 7. https://doi.org/10.1186/s13731018-0086-3

21. Hojeghan, S. B., \& Esfangareh, A. N. (2011). Digital economy and tourism impacts, influences and challenges. Procedia - Social and Behavioral Sciences, 19, 308-316. https://doi.org/10.1016/j.sbspro.2011.05.136

22. In't Veld, J. (2019) The economic benefits of the EU Single Market in goods and services. Journal of Policy Modeling, 41(5), 803-818. https://doi.org/10.1016/j.jpolmod.2019.06.004

23. Larson, J. F. (2017). Networkcentric digital development in Korea: Origins, growth and prospects. Telecommunications Policy, 41(10), 916-930. https://doi. org/10.1016/j.telpol.2017.03.007

24. Linkov, I., Trump, B., PoinsatteJones, K., \& Florin, M.-V. (2018). Governance Strategies for a Sustainable Digital World. Sustainability, 10(2), 1-8. https:// doi.org/10.3390/su10020440

25. Lucendo-Monedero, A. L., RuizRodríguez, F., \& González-Relaño, R. (2019). Measuring the digital divide at regional level. A spatial analysis of the inequalities in digital development of households and individuals in Europe.
Telematics and Informatics, 41, 197-217. https://doi.org/10.1016/j. tele.2019.05.002

26. Milošević, N., Dobrota, M., \& Barjaktarovic Rakocevic, S. (2018). Digital economy in Europe: Evaluation of countries' performances. Zbornik Radova Ekonomskog Fakultet au Rijeci, 36(2), 861-880. Retrieved from https://hrcak.srce. $\mathrm{hr} / 213607$

27. Moroz, M. (2017). The level of development of the digital economy in Poland and selected European countries: a comparative analysis. Foundations of Management, 9(1), 175-190. https://doi.org/10.1515/fman2017-0014

28. Myovella, G., Karacuka, M., \& Haucap, J. (2020). Digitalization and economic growth: A comparative analysis of Sub-Saharan Africa and OECD economies. Telecommunications Policy, 44(2). https://doi.org/10.1016/j.telpol.2019.101856

29. Nambisan, S., Wright, M., \& Feldman, M. (2019). The digital transformation of innovation and entrepreneurship: Progress, challenges and key themes. Research Policy, 48(8), 1-9. https://doi.org/10.1016/j.respol.2019.03.018

30. Nasko, H. (2004). Digitalisierung als Basis für ein neues Zeitalter. In The Digital Economy - Anspruch und Wirklichkeit. Berlin, Heidelberg: Springer.

31. Njoh, A. J. (2018). The relationship between modern Information and Communications Technologies (ICTs) and development in Africa. Utilities Policy, 50, 8390. https://doi.org/10.1016/j. jup.2017.10.005

32. Nwaiwu, F. (2018). Review and Comparison of Conceptual Frameworks on Digital Business Transformation. Journal of Competitiveness, 10(3), 86100. https://doi.org/10.7441/ joc.2018.03.06

33. Pagoropoulos, A., Pigosso, D. C. A., \& McAloone, T. C. (2017). The Emergent Role of Digital Technologies in the Circular 
Economy: A Review. Procedia CIRP, 64, 19-24. https://doi. org/10.1016/j.procir.2017.02.047

34. Park, H. S. (2017). Technology convergence, open innovation, and dynamic economy. Journal of Open Innovation: Technology, Market, and Complexity, 3(24), 1-13. Retrieved from https://jopeninnovation.springeropen.com/ track/pdf/10.1186/s40852-0170074-Z

35. Pereira, A., \& Romero, F. (2017). A review of the meanings and the implications of the Industry 4.0 concept. Procedia Manufacturing, 13, 1206-1214. https://doi. org/10.1016/j.promfg.2017.09.032

36. Pratipatti, S., Gomaa, A. (2019). Analysis of the Impact of the
Indicators in the Networked Readiness Index. Journal of International Technology and Informa tion Management, 28(2), 17-50. Retrieved from https://search. proquest.com/openview/3f2a5ad3 dcbee064d7d8ea631c7bee39/1?pqorigsite $=$ gscholar \&cbl=51771

37. Richardson, L. (2020). Digital and Platform Economies. In International Encyclopedia of Human Geography (2nd ed.). Elsevier Ltd. https://doi.org/10.1016/B978-008-102295-5.10533-5

38. Sturgeon, T. J. (2019). Upgrading strategies for the digital economy. Global Strategy Journal. https://doi. org/10.1002/gsj.1364

39. Sutherland, W., \& Jarrahi, M. H. (2018). The sharing economy and digital platforms: A review and research agenda. International Journal of Information Management, 43, 328-341. https://doi.org/10.1016/j.ijinfomgt.2018.07.004

40. Szeles, M.R. (2018). New insights from a multilevel approach to the regional digital divide in the European Union. Telecommunications Policy, 42(6), 452-463. https://doi. org/10.1016/j.telpol.2018.03.007

41. Vasylenko, Y. A., \& Shevchenko, H. Y. (1979). Analytical Method for Test Finding. Avtomatyka, 2, 3-8.

42. Zhu, X. (2019). Emerging Champions in the Digital Economy. New Theories and Cases on Evolving Technologies and Business Models. Singapore: Springer. 